\title{
Aluminium-iron-amended activated bamboo charcoal (AIAABC) for fluoride removal from aqueous solutions drinking water
}

\author{
Gizachew Wendimu ${ }^{\mathrm{a}}$, Feleke Zewge ${ }^{\mathrm{b}, *}$ and Eyobel Mulugeta ${ }^{\mathrm{c}}$ \\ ${ }^{a}$ Department of Chemistry, College of Natural Sciences, Wolaita Sodo University, P.O. Box \\ 138, Wolaita Sodo, Ethiopia \\ ${ }^{\mathrm{b}}$ Department of Chemistry, College of Natural Sciences, Addis Ababa University, PO Box 1176, \\ Addis Ababa, Ethiopia \\ ${ }^{c}$ Department of Chemistry, College of Natural and Computational Sciences, Ambo University, \\ PO Box 19, Ambo, Ethiopia
}

Wendimu, Gizachew; e-mail: gimesi28@gmail.com

Zewge, Feleke; e-mail: fbeshah@yahoo.com

Mulugeta, Eyobel; e-mail: eyoya2004@yahoo.com

*Corresponding author. Address: Addis Ababa University, Department of Chemistry, P.O. Box 1176, Addis Ababa, Ethiopia.

Fax: +2511112394 70. Tel. +251111239466.

E-mail address: fbeshah@yahoo.com (Feleke Zewge). 


\section{ABSTRACT}

In this study, the adsorption potential of aluminium-iron-amended activated bamboo charcoal (AIAABC), prepared from waste bamboo, for defluoridation of drinking water was investigated. The adsorbent (AIAABC) in which $\mathrm{ABC}$ was impregnated in $\mathrm{AlCl}_{3} / \mathrm{FeCl}_{3}$ solution and treated at $400{ }^{\circ} \mathrm{C}$ showed higher fluoride uptake capacity. The samples obtained were characterized and tested in batch mode. Inorganic particles were dispersed on the surface of carbon as indicated by SEM images and EDS. The main elements found in AIAABC were carbon, oxygen, aluminium, iron, sodium, and sulfur. Fluoride was associated with the aluminium hydro(oxide) (AO) particles in the pore spaces of ABC after adsorption. Specific surface area (SSA) was reduced from 80.5 to $3.7 \mathrm{~m}^{2} / \mathrm{g}$, when $\mathrm{ABC}$ was impregnated with $\mathrm{AO}$, indicating that the $\mathrm{AO}$ particles might cover the surface or pore spaces found in ABC. Maximum adsorption occurred at $\mathrm{pH}$ range from 5-9. The adsorption data were well fitted to Langmuir isotherm model with a maximum adsorption capacity of $21.1 \mathrm{mg} / \mathrm{g}$. The adsorption process obeyed a pseudo-secondorder rate equation. The adsorbent was effectively regenerated $(85.7 \%)$ by $0.1 \% \mathrm{NaOH}$. Due to its high adsorption capacity compared to commercially available aluminium hydroxide-based adsorbents, AIAABC is a highly promising material for defluoridation of drinking water.

Key words: Fluoride; Bamboo waste; Activated charcoal; Adsorption; Aluminium hydro(oxide) 


\section{Introduction}

The level of fluoride in drinking water is a very important physicochemical factor, which must be considered when assessing water quality for human consumption. According to the World Health Organization the maximum acceptable concentration of fluoride ions in drinking water is $1.5 \mathrm{mg} / \mathrm{L}$ [1]. The excess of fluoride in drinking water has been linked to permanent dental and skeletal fluorosis [2]. According to estimates of the Ethiopian Ministry of Water, Energy and Irrigation, more than 11 million people in the Ethiopian Rift Valley rely on drinking water contaminated by fluoride [3].

Defluoridation methods can be broadly divided into four categories based on the fluoride removal mechanism: (co)precipitation, ion-exchange, physical separation and adsorption [4]. Fluoride removal through adsorption onto various materials is the most promising in terms of running costs and ease of operation. The choice of adsorptive medium depends on fluoride uptake capacity, the possibility of regeneration, the number of useful cycles and the end-of-life fate [5].

Several adsorbent materials have been tested in an attempt to identify an efficient and economical defluoridating material [4]. From aluminium hydroxide-based adsorbents, activated alumina (AA) has been extensively studied for years for fluoride removal from drinking water. However, the neutral $\mathrm{pH}$ range the affinity of the surface for fluoride is much lower, limiting the practical applications of the AA. Moreover, it has been reported that alumina begins to leach aluminium and its fluoride complexes below $\mathrm{pH} 6$ and poses severe threats to human health because aluminium and its fluoride complexes are thought to cause Alzheimer's disease and the other health complications [6]. Attempts to increase the uptake capacity of AA with manganese/manganese oxides [7-9], magnesium [10], iron hydroxide/AA mixtures [11], appear to have been successful.

Moreover, adsorption of fluoride by different adsorbents such as fired clay chips [12], waste residue from alum-manufacturing processes [12], untreated hydrated alumina (UHA) and thermally-treated hydrated alumina (THA) obtained from hydrolysis of locally-manufactured aluminium sulphate [13], aluminium oxide-manganese oxide composite material [9], nanoscale aluminium oxide hydroxide $(\mathrm{AlOOH})[3]$ and natural zeolite [14], were among several attempts which have been made in Ethiopia for defluoridation of drinking water. 
Low-cost methods such as adsorption on clays [12,15] and other locally available materials like diatomaceous earth and bone char [15] have been considered in few studies, but still not applicable due to low-fluoride removal efficiency.

Activated carbon is generally recognized as an effective adsorbent due to its high porosity, large surface area, and high catalytic activity, and is currently widely used for the removal of organic compounds in drinking water [16]. However, activated carbon has a relatively small adsorption capacity as well as an affinity for inorganic pollutants such as fluoride. Bone char is the most suitable material for fluoride removal due to its particular chemical composition, which is rich in hydroxyapatite $\left(\mathrm{Ca}_{5}\left(\mathrm{PO}_{4}\right)_{3}(\mathrm{OH})\right)[17,18]$. Although, charring of bones removes organic matter and greatly increases the specific surface area and fluoride adsorption capacity on the bone hydroxyapatite $[19,20]$, religious and cultural beliefs may render cow bone char undesirable in certain regions, including Ethiopia.

Though studies on the application of activated bamboo charcoal for fluoride removal are very limited, few researches have made an attempt to investigate its fluoride removal performance. You and his co-workers [21] were tried to compare the defluoridation effect of bamboo charcoals purchased from different manufactures. The results of experiments indicated that effect of bamboo charcoal of Lishui, Zhejiang on removal of fluoride was achieved $47.8 \%$ under conditions of initial F-concentration $10 \mathrm{mg} / \mathrm{L}$, solid-to-liquid ratio 3:100, $\mathrm{pH}$ value 4.0 , at $25^{\circ} \mathrm{C}$ and shaking rate $100 \mathrm{rpm}$. After modification with $\mathrm{Al}_{2}\left(\mathrm{SO}_{4}\right)_{3}$ and $\mathrm{Fe}_{2}\left(\mathrm{SO}_{4}\right)_{3}$, the fluoride removal performance bamboo charcoals were also improved to $91.8 \%$. This is mainly due to the impregnation of $\mathrm{ABC}$ with metals such as aluminum and iron has significantly increased sorption capacity for fluoride that the host $\mathrm{ABC}$ cannot attract without impregnation. Therefore, the role of $\mathrm{Al} / \mathrm{Fe}$ solution was to effectively introduce surface acidic functional groups to bamboo activated carbons without destruction of pore structure and thus fluoride removal efficiency would also be improved.

Zhang and Wang [22], were also investigated the adsorption capacities of the bamboo-carbon for fluoride from drinking water. They studied the effects of some factors ( $\mathrm{pH}$, quantity of absorbent, absorbing time, regenerating way) on removing fluoride from drinking water. The results have shown that bamboo-carbon have the potential to absorb fluoride from drinking water. 
The arsenic and fluoride removal performance of activated bamboo was also studied by other researchers [23]. Nano-sphere was prepared by carbonizing pieces of bamboo in muffle furnace at $600{ }^{\circ} \mathrm{C}$ under in-sufficient air. The black mass so obtained was functionalized with conc. nitric acid. This was then treated with aluminium sulfate and ferric chloride to increase its absorption efficiencies. It was found that this purification technique is able to remove arsenic and fluoride completely from the water.

To enhance adsorption efficiency, the modification of existing carbon-based adsorbents with suitable chemicals has been investigated with promising results, suggesting that the new adsorbents might remove fluoride from aqueous solutions effectively. This is because, fluoride has a strong affinity towards metal ions including $\mathrm{Al}(\mathrm{III}), \mathrm{Fe}(\mathrm{III})$, and $\mathrm{La}(\mathrm{III})$. Dispersing a mixture of these metals in a protective matrix would limit the total dissolved solids in treated water, and at the same time would provide high fluoride adsorption capacity. For example, maximum fluoride uptake capacity has been achieved by activated carbon impregnating with aluminum or calcium compounds [24, 25].

In addition, the operational costs of adsorption are mainly determined by the price of the adsorbent, and thus there is a growing interest in looking for alternative precursors (i.e., wastes) in AC production. Residues generated during production of bamboo furniture are abundant and not reused in Ethiopia; as a consequence, the activated carbon can be used as low-cost adsorbent or as a support for aluminium oxide for the adsorption of fluoride from drinking water.

Recently, the properties and fluoride-adsorption capacity of an aluminium hydro(oxide) (AO) adsorbent has been investigated [26]. The AO can easily be produced from locally manufactured aluminium sulfate, $\mathrm{Al}_{2}\left(\mathrm{SO}_{4}\right)_{3} \bullet 14 \mathrm{H}_{2} \mathrm{O}$, which is purchased from Awash Melkasa Aluminium Sulfate and Sulfuric Acid Factory, Ethiopia. Laboratory tests have demonstrated a very high removal capacity of about $23.7 \mathrm{mg} / \mathrm{g}$ [13]. Studies so far have indicated that the adsorbent has better performance than activated alumina (AA), which is well known commercially available material for fluoride removal. The AO technology has also been tested as pilot community defluoridation in Ethiopian Rift Valley and showed promising results [27]. However, this highly promising adsorbent needs to be combined with $\mathrm{AC}$ to reduce the cost of production at large scale and also AC is believed to be suitable for removal of other contaminants including fluoride from drinking water. 
The purpose of this study was to prepare low-cost carbons from residues generated during production of bamboo furniture in Ethiopia. Specifically, modified activated bamboo carbon (AIAABC) were prepared following impregnation of aluminium hydro(oxide) onto activated bamboo carbon $(\mathrm{ABC})$. Samples were characterized and the physical and chemical properties were examined. The fluoride removal and regeneration performance of AIAABC was tested in batch experiments.

\section{Materials and methods}

\subsection{Adsorbents}

The ABC adsorbent was prepared from waste bamboo collected from furniture shops, in Ethiopia. Other activated carbons commercially available were also used for comparison. AIAABC was synthesized by immersing $\mathrm{ABC}$ in aluminium salfate solution under constant $\mathrm{pH}$.

\subsubsection{Optimization of the synthesis of $A B C$}

Chemical and thermal activation were used to optimize ABC. Two activating chemicals, such as $\mathrm{H}_{3} \mathrm{PO}_{4}$ and $\mathrm{AlCl}_{3} / \mathrm{FeCl}_{3}$, were used for optimization. Bamboo waste discarded from the production of bamboo furniture was cut into pieces approximately $1 \times 1 \mathrm{~cm}^{2}$ in size. It was washed with distilled water and dried at $105^{\circ} \mathrm{C}$ for $12 \mathrm{~h}$. The first portion of bamboo precursor was immersed in $28 \% \mathrm{H}_{3} \mathrm{PO}_{4}$ (2:1 acid to bamboo ratio) for $1 \mathrm{~h}$ and then separated from the solution and put in an oven overnight at $105{ }^{\circ} \mathrm{C}$. The second portion was immersed in a boiling mixture of $1 \mathrm{M} \mathrm{AlCl}_{3} / \mathrm{FeCl}_{3}$ and heated for $90 \mathrm{~min}$. The samples remained in the mixture at room temperature for $2 \mathrm{~h}$ and filtered out from the solution, then dried in air for $2 \mathrm{~h}$ and later in an oven at $105{ }^{\circ} \mathrm{C}$ for $24 \mathrm{~h}$.

The dried samples were subjected to heat treatment at different temperature $(400,500$ and 600 ${ }^{\circ} \mathrm{C}$ ) in a muffle furnace for $1 \mathrm{~h}$. The carbonization process was carried out in the absence of air. The resulting samples were washed with distilled water until $\mathrm{pH}$ value of the filtrate become steady, and dried. Then the samples were crushed to particle size of less than $0.35 \mathrm{~mm}$ and stored in a desiccator for further investigation. However, the adsorbent (AIAABC) which was activated by $\mathrm{Al} / \mathrm{Fe}$, was selected for further study taking the chemical activation results into consideration. 


\subsubsection{Synthesis of AIAABC}

AIAABC was synthesized from $\mathrm{ABC}$, which was soaked in a $500 \mathrm{~mL}$ solution containing 100 g aluminium sulfate. The mixture was stirred continuously to ensure thorough mixing and the resulting lower $\mathrm{pH}$ (about 3) was adjusted to $\mathrm{pH} 7$ using $2 \mathrm{M} \mathrm{NaOH}$, and then agitated from 1-5 days. Finally, the mixture was filtered and then dried in an oven at $105{ }^{\circ} \mathrm{C}$ then calcined at 300 ${ }^{\circ} \mathrm{C}$ and kept for further analysis and characterization. The AO adsorbent was prepared by following the method stated elsewhere [26].

\subsection{Fluoride analysis}

A fluoride stock solution (1000 mg/L) was prepared from 99.0\% NaF (BDH Chemicals, England) in deionized water. Standards and samples were prepared by appropriate dilution of the stock solution. The fluoride concentration was measured with A pH/ISE (ion selective electrode) meter (Orion model, EA 940 Expandable Ion Analyzer, USA) equipped with combination fluoride selective electrode (Orion Model 96-09, USA). Analyses were performed on equalvolume mixtures of sample and total ionic strength adjustment buffer, the latter being required to suppress interferences.

\subsection{Characterization of the adsorbents}

$\mathrm{X}$-ray diffraction (XRD) analysis of adsorbents was done with a Rigaku Ultima IV powder $\mathrm{X}$-ray diffractometer with $\mathrm{Cu} \mathrm{K} \alpha$ radiation and Bragg-Brentano optics. McCrone micronizing mill was used for crushing, grinding, and homogenizing the samples for XRD analysis. Samples were characterized by scanning electron microscopy with energy dispersive $\mathrm{X}$-ray spectroscopy (SEM/EDS) using a Zeiss Neon SEM operating at $10 \mathrm{kV}$. Specific surface area (SSA) was determined using BET analysis using a Quantachrome Autosorb Automated Gas Sorption System with a Beckman Coulter SA-3100 Surface Area Analyzer and $\mathrm{N}_{2}$ adsorption. The point of zero charge (PZC) was measured by potentiometric mass titrations technique [28]. PZC was identified as the common intersection point (CIP) of the potentiometric curve of the blank solution with the corresponding curves of the impregnating suspensions containing 0.5, 1.0, and $1.5 \mathrm{~g}$ of the adsorbent in electrolytic solution $\left(50 \mathrm{~mL}\right.$ of $\left.0.03 \mathrm{M} \mathrm{NaNO}_{3}\right)$. The experiment was performed, under a $\mathrm{N}_{2}$ atmosphere and the aqueous suspensions were equilibrated for $1 \mathrm{~h}$ to reach an equilibrium $\mathrm{pH}$ value. Small amount of $1 \mathrm{M} \mathrm{NaOH}$ was added to make the $\mathrm{pH}$ around 
10 and recorded as initial $\mathrm{pH}$ after $15 \mathrm{~min}$. Then the solid suspensions were titrated by $0.1 \mathrm{M}$ $\mathrm{HNO}_{3}$, using 665 Dosimat (Metrohm, Switzerland). The $\mathrm{pH}$ of each suspension was then measured at 2 min time interval using a digital $\mathrm{pH}$ meter standardized by buffers (WTW Inolab pH/ION Level 2, Germany). The concentration of total acidic and basic groups on AIAABC surface was determined from $\mathrm{NaOH}$ and $\mathrm{HCl}$ uptake, respectively. $100 \mathrm{mg}$ of AIAABC samples were placed in $50 \mathrm{~mL}$ of $0.05 \mathrm{M} \mathrm{NaOH}$ or $0.05 \mathrm{M} \mathrm{HCl}$. Sealed beakers that contained samples or blanks were shaken for $24 \mathrm{~h}$ and filtered. Then, $10 \mathrm{~mL}$ of each filtrate were titrated with $0.05 \mathrm{M}$ of either $\mathrm{NaOH}$ or $\mathrm{HCl}$ solution. The difference between $\mathrm{NaOH}$ and $\mathrm{HCl}$ consumption by the blank and samples was calculated and translated to the equivalent acid or base content per gram of the solid adsorbent [29].

\subsection{Batch adsorption experiments}

All the batch experiments were conducted in $500 \mathrm{~mL}$ Erlenmeyer flask containing $500 \mathrm{~mL}$ of fluoride spiked deionized water at room temperature $\left(23 \pm 2{ }^{\circ} \mathrm{C}\right)$ to evaluate fluoride removal efficiency and capacity of the adsorbent under continuous mixing condition with magnetic stirrer. A sample solution was periodically taken out of the flask and filtered through a $0.45 \mu \mathrm{m}$ filter paper for fluoride analysis. All the experiments were performed in triplicate and the mean values were used.

The amount of fluoride adsorbed per unit mass of the adsorbent at any time $\mathrm{t}\left(\mathrm{q}_{\mathrm{t}}, \mathrm{mg} / \mathrm{g}\right)$, and the adsorption efficiency $(\% \mathrm{R}$, determined as the fluoride removal percentage relative to the initial concentration) of the system, was calculated as:

$\mathrm{q}_{\mathrm{t}}=\left[\frac{\mathrm{C}_{\mathrm{o}}-\mathrm{C}_{\mathrm{t}}}{\mathrm{m}}\right] \times \mathrm{V}$

$\% R=\left[\frac{C_{o}-C_{t}}{C_{o}}\right] \times 100$

where, $\mathrm{C}_{\mathrm{o}}$ and $\mathrm{C}_{\mathrm{t}}$ are the fluoride concentrations in solution $(\mathrm{mg} / \mathrm{L})$ initially and at any time $(\mathrm{t})$, respectively, $\mathrm{m}$ the mass of the adsorbent $(\mathrm{g})$ and $\mathrm{V}$ is the volume $(\mathrm{L})$ of the solution.

\subsubsection{Effect of process parameters on fluoride removal efficiency of $A I A A B C$}

The effect of dose and contact time of AIAABC, initial fluoride concentration, solution $\mathrm{pH}$ and co-existing ions were investigated by varying any one of the parameters and keeping the 
other parameters constant. The effect of adsorbent dose and contact time were studied by varying the dosage in the range of 0.4 to $2.5 \mathrm{~g} / \mathrm{L}$ at constant initial fluoride concentration of $10 \mathrm{mg} / \mathrm{L}$. The dosage range was selected based on initial preliminary screening experiments. To investigate the effect of initial concentration, experiments were conducted at various fluoride concentrations ranging from 5 to $40 \mathrm{mg} / \mathrm{L}$ at constant adsorbent dose of $0.8 \mathrm{~g} / \mathrm{L}$. The effect of initial solution $\mathrm{pH}$ on fluoride adsorption was evaluated by varying the solution $\mathrm{pH}$ from 3-11. The $\mathrm{pH}$ was adjusted to the desired level either with $0.1 \mathrm{M} \mathrm{NaOH}$ or $0.1 \mathrm{M} \mathrm{HCl}$. The meter was calibrated each time measurements were being performed by using $\mathrm{pH}$ calibration buffers. To investigate the effect of anions $\left(\mathrm{SO}_{4}{ }^{2-}, \mathrm{Cl}^{-}\right.$and $\left.\mathrm{HCO}_{3}{ }^{-}\right)$on fluoride adsorption by AIAABC $(0.8$ $\mathrm{g} / \mathrm{L})$, the solutions of the required concentration of anions $(100-500 \mathrm{mg} / \mathrm{L})$ were prepared by dissolving the sodium salts of the respective anions in distilled water containing $10 \mathrm{mg} / \mathrm{L}$ fluoride. The $\mathrm{pH}$ of the solution was controlled at $7.0 \pm 0.2$.

\subsubsection{Adsorption isotherms and kinetics}

The adsorption isotherm experiments were conducted using an adsorbent dose of $0.8 \mathrm{~g} / \mathrm{L}$ and varying initial fluoride concentrations ranging from $5-40 \mathrm{mg} / \mathrm{L}$. The kinetic analysis of the adsorption data is based on reaction kinetics of pseudo-first-order and pseudo-second-order reaction mechanisms. Adsorption kinetics was determined using constant surface loading of 12.5 $\mathrm{mg} / \mathrm{g}(0.4,0.8$ and $1.6 \mathrm{~g} / \mathrm{L}$ of adsorbent) for the corresponding fluoride concentration of 5, 10 and $20 \mathrm{mg} / \mathrm{L}$, respectively.

\subsubsection{Desorption studies}

To investigate desorption of fluoride from saturated adsorbent, $0.8 \mathrm{~g} / \mathrm{L}$ dose of AIAABC was added into $10 \mathrm{mg} / \mathrm{L}$ fluoride solution and equilibrated for $180 \mathrm{~min}$. Then, the solution was filtered and the concentration of fluoride in the filtrate was measured to determine the amount of fluoride on the adsorbent [30]. The exhausted adsorbent was conditioned in $50 \mathrm{~mL}$ of $0.1,1$ and $5 \% \mathrm{NaOH}$ solution. Samples were taken after 30 and $60 \mathrm{~min}$ and concentration of fluoride was determined from which the elution potential of the eluent be calculated.

\section{Results and discussion}

\subsection{Effect of aluminium loading}


The optimization of the adsorbent (AIAABC) is shown in Fig. 1. The adsorbent with 1:1 ratio of $\mathrm{AO}: \mathrm{ABC}$, where $\mathrm{ABC}$ was chemically activated with $1 \mathrm{M} \mathrm{AlCl}_{3} / \mathrm{FeCl}_{3}$ and treated at $400{ }^{\circ} \mathrm{C}$ showed greater fluoride removal efficiency at $48 \mathrm{~h}$ agitation time. Moreover, the percentage fluoride removal efficiency increases from 24 to $48 \mathrm{~h}$ and then gradually decreases as agitation time increases from 48 to $120 \mathrm{~h}$ at $400{ }^{\circ} \mathrm{C}$. This is because; carbonization process leads to deterioration of the proper structure of the activated carbon and thus some of the pores were clogged due to the excessive filling of the pores [31]. This might also be due to the proper impregnation of $\mathrm{Al} / \mathrm{Fe}$ oxides in to the charcoal. $\mathrm{Fe}^{3+}$ and $\mathrm{Al}^{3+}$ ions have good affinity with fluoride anions, because of the hard-hard combination, in agreement with the soft-hard acid base (SHAB) concept. Al(III) is frequently used in defluoridation. A nano-scale dispersion of the inorganic adsorbent into the charcoal may be an interesting way to an efficient fluoride scavenger [29].

In the chemical activation process, carbonization temperature and time are important preparation variables. Lignocellulosic composition of the biomass has a significant effect on micropore structure of the end product i.e. activated carbon. Researchers confirmed that lignin is the main source of char, whereas cellulose and hemicelluloses are the volatile fractions of biomass. Lignin decomposition starts at low temperatures $\left(160-170{ }^{\circ} \mathrm{C}\right)$ and this process continues at low rate until elevated temperature of $900{ }^{\circ} \mathrm{C}$. The second component which starts to decompose is hemicellulose, followed by cellulose. The decomposition of these two polymers takes place in a narrow temperature range of about $200-400{ }^{\circ} \mathrm{C}$. Chemical activation does not require as high temperatures as physical activation [32]. The carbonization of impregnated bamboo also leads to charcoals with a high content of inorganic compounds. This is because, as the wood carbonization temperature increased, the carbon content in the adsorbent decreased, while the inorganic matter content increased. This was due to the fact that increasing carbonization temperature enhanced the combustion of cellulose, hemicelluloses and lignin which are the main constituents of wood [33].

Fluoride removal efficiency (about 74\%) was obtained from $\mathrm{H}_{3} \mathrm{PO}_{4}$ activation and calcination of $\mathrm{ABC}$ at $600{ }^{\circ} \mathrm{C}$, where the $\mathrm{AO} / \mathrm{ABC}$ mixture (1:1 ratio) and the agitation time were 5 days (date not shown). The efficiency would further enhance if the activation temperature and acid to bamboo ratio were optimized [34]. 


\subsection{Characteristics of the adsorbents}

The XRD diffractogram pattern of AIAABC indicated that it is mainly amorphous and most peaks corresponds to $\mathrm{Ca}_{3} \mathrm{Al}_{2} \mathrm{O}_{6}$ (data not shown). It is known that amorphous materials have good adsorbent properties due to their high specific surface area and more active sites on their surfaces [35]. The presence of aluminium oxides in AIAABC structure was also confirmed by XRD analysis.

The SEM-EDS analysis of both ABC and AIAABC showed that, the matrix carbon had shown an irregular shaped layer on the surface of ABC (Fig. 2a). The EDS spectrum of Fig. 2b showed the presence of $\mathrm{C}, \mathrm{O}, \mathrm{K}, \mathrm{Fe}$ and $\mathrm{Na}$ as major elements in the ABC. In Fig. 2c, there were particles dispersed unevenly on the surface of AIAABC, which are attributed to the formation of an inorganic layer (oxides of $\mathrm{Fe} / \mathrm{Al}$ ) on the charcoal during the wood carbonization. Since wood has an anisotropic structure, it is not surprising that the wood impregnation was not a uniform step leading to a similar repartition of these particles on the charcoals [29]. It was also confirmed by EDS (Fig. 2d), that there was a successful impregnation of aluminum on to ABC. The amount of Al, C, S, and Na loaded on AIAABC was 25, 675, 3 and $5 \mathrm{mg} / \mathrm{g}$, respectively. Fig. 2f showed the chemical composition of AIAABC after adsorption of fluoride, and it can be concluded that fluoride is highly associated with the AO particles present in the pore spaces ABC (Fig. 2e).

The reduction of the specific surface area (SSA) from 80.5 to $3.7 \mathrm{~m}^{3} / \mathrm{g}$, when the $\mathrm{ABC}$ was impregnated with AO, was attributed to the impregnation of AO particles on the surface or pore spaces found in $\mathrm{ABC}$. Calcination of AIAABC to a temperature of $300{ }^{\circ} \mathrm{C}$ might cause change in surface morphology of the adsorbent.

The surface of AIAABC was positively charged when solution $\mathrm{pH}$ was below its PZC (9.6), facilitating fluoride adsorption through the electrostatic attraction between fluoride and adsorbent. The results of the acid-base titration to determine surface acidic and basic groups of AIAABC are shown in Table 1. The analysis of these data provided evidence that upon aluminum amendment, the concentration of the total acidic sites increased than basic sites. This is due to the amphoteric character of the oxides of aluminum and iron, and in this case they behave like acids. Thus, it was reasonable to assume that fluoride was adsorbed to acidic sites on the aluminum-amended carbon. 


\subsection{Fluoride removal performance under different operating conditions}

The percentage removal of fluoride increases significantly up to an adsorbent dose of $0.8 \mathrm{~g} / \mathrm{L}$, however no significant change was observed beyond this dose under the experimental conditions used (Fig. 3). The increase in fluoride removal efficiency was due to the large number of available fluoride binding sites resulting from the increased in adsorbent dosage [12]. Conversely, the adsorption capacity decreases with increasing dose (Fig. 3), this possibly due to constant initial fluoride concentration $(10 \mathrm{mg} / \mathrm{L})$. To maintain reasonable capacity and high removal efficiency, the surface loading for optimum fluoride removal (about 90\%), which corresponds to a dose of $0.8 \mathrm{~g} / \mathrm{L}$ (capacity of about $11.16 \mathrm{mg} \mathrm{F}^{-} / \mathrm{g}$ of adsorbent), was considered for further experiments.

The rate of removal of fluoride is fast during the first $30 \mathrm{~min}$ (Fig. 4a). After $30 \mathrm{~min}$, the rate of removal of fluoride decreases and reaches equilibrium within $180 \mathrm{~min}$. The time to reach equilibrium appears to be independent of adsorbent dose under the experimental conditions used for this study. However, after $30 \mathrm{~min}$ the rate of change in fluoride concentration was smaller for higher adsorbent doses $(\geq 0.8 \mathrm{~g} / \mathrm{L})$. The fast uptake capacity obtained at the initial stage may be explained by an increased availability in the number of active binding sites on the adsorbent surface. The slow and insignificant adsorption observed as time progresses is due to the fact that every adsorbent has a limited number of active sites and saturated with increasing time.

As shown in Fig. 4b, the efficiency increases with decreasing initial fluoride concentration at the initial stage of adsorption. It can also be observed that the adsorption of fluoride from water is relatively more rapid at lower initial concentrations. Thus, the initial fluoride concentration had an influence on the equilibrium sorption time, and significant fluoride removal efficiency (more than 90\%) was observed when the initial fluoride was less than or equal to $10 \mathrm{mg} / \mathrm{L}$ for a contact time of $180 \mathrm{~min}$. However, adsorption of more concentrated fluoride solution approached equilibrium slowly. On the other hand, the adsorption capacity increases with an increase in the initial concentration. This may be due to the availability of a higher number of fluoride ions per unit mass of the adsorbents and/or the utilization of less accessible or energetically less-active sites because of increasing diffusivity of fluoride ions when initial concentration increases [36].

The experimental results of the effect of solution $\mathrm{pH}$ on the adsorption of fluoride are shown in Fig. 5. In the literature, maximum fluoride adsorption was obtained in the $\mathrm{pH}$ range of 4.010.0 by using iron(III)-aluminum(III) mixed oxide [11], whereas it was obtained at pH 7 using 
activated alumina [37]. It was also evident that the charcoals exhibited significantly fluoride removal in the acidic $\mathrm{pH}$ range [29]. Thus, the electrostatic attraction between charcoal surfaces and fluoride ions plays a small part in the fluoride adsorption. In our work, the adsorption of fluoride increased from $\mathrm{pH} 3$ to 9 reached a maximum of about $90.3 \%$ at $\mathrm{pH}$ 9. Further increase in the solution $\mathrm{pH}$ from 9-11 decreases the fluoride removal efficiency and was significant after $\mathrm{pH}$ of 9. The decrease in the fluoride removal below $\mathrm{pH} 5$ was possibly due to the protonation of the fluoride ion and formation of weakly ionized hydrofluoric acid [38]. On the other hand, at a $\mathrm{pH}$ above 9, fluoride removal efficiency decreased possibly due to the surface acquires negative charge in alkaline $\mathrm{pH}$ and hence there was repulsion between the negatively charged surface and fluoride also there would be stronger competition from hydroxide ions [12]. The fluoride adsorption capacity of this medium was more enhanced in the $\mathrm{pH}$ range from 5 to 9 , which is more suitable for practical applications and makes it possible to avoid $\mathrm{pH}$ adjustment with the associated cost and operational difficulties, especially if it is to be used in remote areas of developing countries. In addition, the concentration of aluminium in the treated water was in the range of 0.03 to $0.07 \mathrm{mg} / \mathrm{L}$ in the $\mathrm{pH}$ range between 6.5 to 8.0 , which is below the WHO recommended value for drinking water.

The effect of co-existing anions on fluoride removal efficiency by AIAABC is shown in Fig. 6. In the absence of other anions, about $88 \%$ of fluoride was adsorbed. The results also show that $\mathrm{Cl}^{-}$and $\mathrm{SO}_{4}{ }^{2-}$ have no substantial effect on fluoride adsorption. However, the presence of $\mathrm{HCO}_{3}{ }^{-}$ ions decreased the fluoride adsorption capacity; this is most likely to be related to an increase in $\mathrm{pH}$ with increasing $\mathrm{HCO}_{3}{ }^{-}$content. Maliyekkal et al. [10], have also reported a similar observation for the removal of fluoride using a new adsorbent material, magnesia amended activated alumina.

\subsection{Adsorption isotherms and kinetics}

The determined coefficients for isotherm and kinetic models are summarized in Tables 2 and 3, respectively. Fig. 7 and 8 were plotted using the experimental and predicted value by linear regression methods for isotherm and kinetics models, respectively. From Table 2, it was observed that the correlation coefficient value for the linear form of the Langmuir isotherm is higher $\left(\mathrm{R}^{2}=0.9988\right)$ than Freundlich and $\mathrm{D}-\mathrm{R}$ isotherms. Therefore, the Langmuir isotherm is the best-fit isotherm for the adsorption of fluoride on to AIAABC under the experimental 


\section{Page 14 of 29}

conditions used in this study. Thus, the maximum adsorption capacity $\left(\mathrm{q}_{\mathrm{m}}\right)$ was found to be 21.1 $\mathrm{mg} / \mathrm{g}$.

By the linear method pseudo-second-order kinetics very well represent the kinetic uptake of fluoride onto AIAABC. The rate constants for the three initial concentrations were very close and therefore, the three constants were averaged to obtain a single rate constant of $9.41 \times 10^{-2}$ $\mathrm{g} / \mathrm{min} \mathrm{mg}$.

The results were also analyzed in terms of intraparticle diffusion model to investigate whether the intraparticle diffusion was the rate controlling step in adsorption of fluoride on to AIAABC. The model used here was adopted from Deryło-Marczewska and his co-workers [39] propesed by Weber and Morris [37]. If a plot of $\mathrm{q}_{\mathrm{t}}$ versus $\mathrm{t}^{1 / 2}$ gives a straight line that pass through the origin, then it suggests that the intraparticle diffusion contributes predominantly in the ratedetermining step [37]. However, if the data exhibit multi-linear plots, then it is anticipated that other mechanisms are also involved along with intraparticle diffusion. Thus, as can be seen from Fig. 9 different regions can be identified which indicates different mechanisms. The instant initial linear and subsequent curved portion reflects the external surface adsorption and film or boundary layer diffusion effect [37]. Based on the result it may be concluded that the adsorption mechanism of fluoride ion by AIAABC from aqueous solution is complex process and the intraparticle diffusion was not the only rate controlling step. Since, the linear portion of the curve does not pass the origin and this result is consistent with the work of other studies [40] and [41].

\subsection{Desorption study}

The results of elution of fluoride under various concentrations of $\mathrm{NaOH}$ and time are indicated in Fig. 10. Desorption of fluoride from AIAABC was highest using $1 \% \mathrm{NaOH}$ after $1 \mathrm{~h}$ $(85.71 \%)$. The desorption of fluoride from the solid surface seems a faster process as compared to the adsorption. It was also found that the adsorption efficiency drops to $82 \%$ during the second cycle, suggesting that the adsorbent can be reused. Based on the results of desorption and readsorption, it can be concluded that regeneration is promising if the conditions are optimized by further studies. 


\section{Comparison of defluoridation capacities}

Comparison of adsorption capacity was made for selected adsorbents. The results in Table 4 clearly indicate that AIAABC has a much higher defluoridation capacity than other adsorbents except AO. The adsorption capacity of AIAABC was 4.88 times higher than ABC without AO treatment (data not shown). This is due to the impregnation of AO, which is highly associated with fluoride, inside the pore space of $\mathrm{ABC}$ as indicated in Fig. 2e and from reduction of the SSA. The use of AIAABC as a defluoridation media could have advantage over AO in that its production cost is much lower for application in the field and also the AC would also remove other drinking water contaminants such as synthetic organics and heavy metals [42]. Comparison of defluoridation capacities shows AIAABC is a promising sorbent for removal of excess fluoride from drinking water.

\section{Conclusions}

The present study has shown that aluminium amended activated bamboo charcoal prepared from waste bamboo can be employed as effective and low cost adsorbent for the removal of fluoride from aqueous solution. The AIAABC which was pre-treated by $\mathrm{Al} / \mathrm{Fe}$ at $400{ }^{\circ} \mathrm{C}$ shows higher fluoride uptake capacity for defluoridation of drinking water as compared to other adsorbents. The uptake of fluoride in $\mathrm{pH}$ range from 5-9 was higher and decreases with increasing $\mathrm{pH}$. The equilibrium adsorption data fitted well with Langmuir isotherm model. It was also observed that the presence of certain co-existing ions (sulfate and chloride) have negligible effect on removal of fluoride, while bicarbonate anion shows deleterious effect. The rate of adsorption was fairly rapid and maximum fluoride uptake was attained within $3 \mathrm{~h}$. Therefore, AIAABC is a promising low cost adsorbent for defluoridation of drinking water in high fluoride concentration areas.

\section{Acknowledgments}

This research was supported by the National Science Foundation (NSF) and USAID PEER [grant number AID-OAA-A-11-00012] to Feleke Zewge. We thank University of Oklahoma School of Geology and Geophysics for doing the XRD, SEM/EDS and SSA analyses. 


\section{References}

[1] WHO, Guidelines for drinking water quality, fourth ed. World Health Organization, Geneva, Switzerland, 2011.

[2] Q. Gua, Q. Guo, Water defluoridation by hydrotalcite and takovite and subsequent formation of new fluoride-bearing phases, Environ. Technol. 34 (2013) 1053-1062.

[3] F. Adeno, E. Mulugeta, F. Zewge, Y. Chebude, Adsorptive removal of fluoride from water using nanoscale aluminium oxide hydroxide (AlOOH), Bull. Chem. Soc. Ethiop. 28 (2014) $215-227$.

[4] J. Sneha, K.Y. Mahesh, L. Nitin, R. Sadhana, Fluoride in drinking water and defluoridation of water, Chem. Rev. 112 (2012) 2454-2466.

[5] L. Osterwalder, C.A. Johnson, H. Yang, R.B. Johnston, Multi-criteria assessment of community-based fluoride-removal technologies for rural Ethiopia, Sci. Total Environ. 488 (2014) 532-538.

[6] S. George, P. Pandit, A.B. Gupta, M. Agarwal, Modeling and simulation studies for aluminium-fluoride interactions in Nalgonda defluoridation process, Chemical Products and Process Modeling Vol 4, The Berkeley Electronic Press, Berkeley, 2009.

[7] S.S. Tripathy, A.M. Raichur, Abatement of fluoride from water using manganese dioxide coated activated alumina, J. Hazard. Mater. 153 (2008) 1043-1051.

[8] S.X. Teng, S.G. Wang, W.X. Gong, X.W. Liu, B.Y. Gao, Removal of fluoride by hydrous manganese oxide-coated alumina: performance and mechanism, J. Hazard. Mater. 168 (2009) 1004-1011.

[9] S. Alemu, E. Mulugeta, F. Zewge, B.S. Candravanshi, Water defluoridation by aluminium oxide-manganese oxide composite material, Environ. Techno. 35 (2014) 1893-1903.

[10] S.M. Maliyekkal, A.S. Shukla, L. Philip, M.N. Indumathi, Enhanced fluoride removal from drinking water by magnesia-amended activated alumina granules, J. Chem. Eng. 140 (2008) 183-192.

[11] K. Biswas, S.K. Saha, U.C. Ghosh, Adsorption of fluoride from aqueous solution by a synthetic iron(III)-aluminium(III) mixed oxide, Ind. Eng. Chem. Res. 46 (2007) 5346-5356.

[12] G. Moges, F. Zewge, M. Socher, Preliminary investigations on the defluoridation of water using fired clay chips, J. Afr. Earth Sei. 21 (1996) 479-482. 
[12] W. Nigussie, F. Zewge, B.S. Chandravanshi, Removal of excess fluoride from water using waste residue from alum manufacturing process, J. Hazard. Mater. 147 (2007) 954-963.

[13] B. Shimelis, F. Zewge, B.S. Chandravanshi, Removal of excess fluoride from water by aluminium hydroxide, Bull. Chem. Soc. Ethiop. 20 (2006) 17-34.

[14] L. Gómez-Hortigüela, J. Pérez-Pariente, R. García, Y. Chebude, I. Díaz, Natural zeolites from Ethiopia for elimination of fluoride from drinking water, Sep. Purif. Technol. 120 (2013) 224-229.

[15] Z. Feleke, A. Bekele, Alem Tena Catholic Church Defluoridation Pilot Study, A report submitted to the Ethiopian Science and Technology Commission, Addis Ababa, Ethiopia, 2000.

[16] R.C. Bansal, M. Goyal, Activated carbon adsorption, CRC Press, USA, 2005.

[17] V. Hernández-Montoya, M.P. Elizalde-González, R. Trejo-Vázquez, Screening of commercial sorbents for removal of fluoride in synthetic and groundwater, Environ. Technol. 28 (2007) 595-607.

[18] I. Abe, S. Iwasaki, T. Tokimoto, N. Kawasaki, T. Nakamura, S. Tanada, Adsorption of fluoride ions onto carbonaceous materials, J. Colloid Interface Sci. 275 (2004) 35-39.

[19] C.K. Rojas-Mayorga, A. Bonilla-Petriciolet, I.A. Aguayo-Villarreal, V. HernandezMontoya, M.R. Moreno-Virgen, R. Tovar-Gomez, M.A. Montes-Moran, Optimization of pyrolysis conditions and adsorption properties of bone char for fluoride removal from water, J. Anal. Appl. Pyrol. 104 (2013) 10-18.

[20] R. Tovar-Gomez, M.R. Moreno-Virgen, J.A. Dena-Aguilar, V. Hernandez-Montoya, A. Bonilla-Petriciolet, M.A. Montes-Moran, Modeling of fixed-bed adsorption of fluoride on bone char using a hybrid neural network approach, Chem. Eng. J. 228 (2013) 1098-1109.

[20] J. Christoffersen, M.R. Christoffersen, R. Larsen, I.J. Moller, Regeneration by surfaceceating of bone char used for defluoridation of water, Water Res. 25 (1991) 227229.

[21] M.J. Larsen, E.I.F. Pearce, G. Ravnholt, The effectiveness of bone char in the defluøridation of water in relation to its crystallinity, carbon content and dissolution pattern, Arch. Oral Biol. 39 (1994) $807-816$.

[21] F. You, B. Peng, L. Chai, H. Gao, A. Mao, Study on fluoride removal from drinking water by modified bamboo charcoal, Environ. Sci. Mgt. 23 (2008) 36-47. 
[22] Q.W. Zhang, G.X. Wang, Research on removing effects of the bamboo carbon fro fluoride from drinking water, Trace Elem. Sci. 12 (2005) 63-66.

[23] S. Das, Preparation of carbon nanosphere from bamboo and its use in water purification, Current Trends in Technology and Science, Tripura, India, 2012.

[24] E. Tchomgui-Kamga, V. Alonso, C.P. Nanseu-Njiki, N. Audebrand, E. Ngameni, A. Darchen, Preparation and characterization of charcoals that contain dispersed aluminium oxide as adsorbents for removal of fluoride from drinking water, Carbon 48 (2010) 333-343.

[25] E. Tchomgui-Kamga, E. Ngameni, A. Darchen, Evaluation of removal efficiency of fluoride from aqueous solution using new charcoals that contain calcium compounds, J. Colloid Interface Sci. 346 (2010) 494-499.

[26] E. Mulugeta, F. Zewge, C.A. Johnson, B.S. Chandravanshi, A high-capacity aluminium hydroxide-based adsorbent for water defluoridation, Desalin. Water Treat. 52 (2014) 54225429.

[27] E. Mulugeta, F. Zewge, C.A. Johnson, B.S. Chandravanshi, Aluminium hydro(oxide)-based (AO) adsorbent for defluoridation of drinking water: Optimisation, performance comparison, and field testing, Water SA 41 (2015) 121-128.

[28] K. Bourikas, J. Vakros, C.H. Kordulis, A. Lycourghiotis, Potentiometric mass titrations: experimental and theoretical establishment of a new technique for determining the point of zero charge (PZC) of metal (hydr)oxides, J. Phy. Chem. 107 (2003) 9441-9451.

[29] T. Eric, A. Ve'ronique, P. Charles, A. Nathalie, N. Emmanuel, D. Andre, Preparation and characterization of charcoals that contain dispersed aluminum oxide as adsorbents for removal of fluoride from drinking water, Carbon 48 (2010) 333-343.

[30] S.M. Maliyekkal, A.K. Sharma, L. Philipet, Manganese-oxide-coated alumina: A promising sorbent for defluoridation of water, Water Res. 40 (2006) 3497-3506.

[31] A.R. Mohamed, M. Mohammadi, G.N. Darzi, Preparation of carbon molecular sieve from lignocellulosic biomass: A review, Renew. Sustainable Energy Rev. 14 (2010) 1591-1599.

[32] Gozde Duman, Cagdas Okutucu, Suat Ucar, Ralph Stahl, Jale Yanik, The slow and fast pyrolysis of cherry seed, Bioresour. Technol. 102 (2011) 1869-1878.

[30] J. Gonzalez, J. Encinar, J. Canito, E. Sabio, M. Chacon, Pyrolysis of cherry stones: energy uses of the different fractions and kinetic study, J. Anal. Appl. Pyrol.67 (2003) 165-190. 
[33] K. Bru, J. Blin, A. Julbe, G. Volle, Pyrolysis of metal impregnated biomass: an innovative catalytic way to produce gas fuel, J. Anal. Appl. Pyrol. 78 (2007) 291-300.

[34] L.S. Chan, W.H. Cheung, S.J. Allen, G. McKay, Separation of acid-dyes mixture by bamboo derived active carbon, Sep. Purif. Techno. 67 (2009) 166-172.

[35] G. Zhang, J. Qu, L. Huijuan, R. Liu, R. Wu, Preparation and evaluation of a novel Fe-Mn binary oxide adsorbent for effective arsenite removal, Water Res. 41 (2007) 1921-1928.

[36] M. Karthikeyan, K.K. Satheesh, K.P. Elango, Studies on the defluoridation of water using conducting polymer/montmorillonite composites, Environ. Technol. 33 (2012) 733-739.

[37] S. Ghorai, K.K. Pant, Equilibrium, kinetics and breakthrough studies for adsorption of fluoride on activated alumina, Sep. Purif. Technol. 42 (2005) 265-271.

[38] A.M. Raichur, M.J. Basu, Adsorption of fluoride onto rare earth oxides, Sep. Purif. Technol. 24 (2001) 121-127.

[39] A. Deryło-Marczewska, K. Miroslaw, A.W. Marczewski, D. Sternik, Studies of adsorption equilibria and kinetics in the systems: aqueous solution of dyes-mesoporous carbons, Appl. Surf. Sci. 256 (2010) 1164-1170.

[37] W.J. Weber, J.C. Morris, Kinetics of adsorption on carbon from solution, J. Saint Eng. Div. ASCE. 89 (1963) 3159.

[40] C.S. Sundaram, N. Viswanathan, S. Meenakishi, Fluoride sorption by nanohydroxyapatite/Chitin composite, J. Hazard. Mater. 172 (2009) 147-151.

[41] S. Meenakshi, C.S. Sundaram, R. Sukumar, Enhanced fluoride sorption by mechanochemically activated Kaolinites, J. Hazard. Mater. 153 (2008) 164-172.

[42] V. Hernandez-Montoya, D.I. Mendoza-Castillo, A. Bonilla-Petriciolet, M.A. MontesMoran, M.A. Perez-Cruz, Role of the pericarp of Carya illinoinensis as biosorbent and as precursor of activated carbon for the removal of lead and acid blue 25 in aqueous solutions. J. Anal. Appl. Pyrol. 92 (2011) 143-151.

[43] R.S. Sathish, N.S.R. Raju, G.S. Raju, G.N. Rao, K.A. Kumar, C. Janardhana, Equilibrium and kinetic studies for fluoride adsorption from water on zirconium impregnated coconut shell carbon, Sep. Sci. Technol. 42 (2007) 769-788.

[44] N. Chen, Z. Zhang, C. Feng, D. Zhu, Y. Yang, N. Sugiura, Preparation and characterization of porous granular ceramic containing dispersed aluminum and iron oxides as adsorbents for fluoride removal from aqueous solution, J. Hazard. Mater. 186 (2011) 863-868. 
[45] A.A.M. Daifullah, S.M. Yakout, S.A. Elreefy, Adsorption of fluoride in aqueous solutions using $\mathrm{KMnO}_{4}$-modified activated carbon derived from steam pyrolysis of rice straw, J. Hazard. Mater. 147 (2007) 633-643.

Table 1. Surface site concentration of acidic and basic groups; PZC, and SSA of AIAABC.

\begin{tabular}{|c|c|c|c|}
\hline Acidic $(\mathbf{m m o l} / \mathbf{g})$ & Basic $(\mathbf{m m o l} / \mathbf{g})$ & $\mathbf{P Z C}$ & $\left.\mathbf{S S A ~} \mathbf{~ m}^{2} / \mathbf{g}\right)$ \\
\hline 0.75 & 0.125 & 9.6 & 3.7 \\
\hline
\end{tabular}

Table 2. Linear isotherm equations and parameters.

\begin{tabular}{|c|c|c|c|c|}
\hline Isotherms & Regression equations & \multicolumn{3}{|c|}{ Linear } \\
\hline \multirow{3}{*}{$\begin{array}{l}\text { Langmuir: } \\
\qquad \frac{\mathrm{C}_{\mathrm{e}}}{\mathrm{q}_{\mathrm{e}}}=\mathrm{b} \frac{1}{\mathrm{q}_{\mathrm{m}}}+\frac{\mathrm{C}_{\mathrm{e}}}{\mathrm{q}_{\mathrm{m}}}\end{array}$} & \multirow{3}{*}{$y=0.0474 x+0.0612$} & \multicolumn{3}{|c|}{ Parameters } \\
\hline & & $\begin{array}{c}\mathrm{q}_{\mathrm{m}} \\
(\mathrm{mg} / \mathrm{g})\end{array}$ & $\mathrm{b}(\mathrm{L} / \mathrm{mg})$ & $\mathrm{R}^{2}$ \\
\hline & & 21 & 0.06 & 0.9988 \\
\hline \multirow{3}{*}{$\begin{array}{l}\text { Freundlich: } \\
\log \left(\mathrm{q}_{\mathrm{e}}\right)=\log \left(\mathrm{K}_{\mathrm{F}}\right)+\frac{1}{\mathrm{n}} \log \left(\mathrm{C}_{\mathrm{e}}\right)\end{array}$} & \multirow{3}{*}{$\mathrm{y}=0.2959 x+0.9565$} & \multicolumn{3}{|c|}{ Parameters } \\
\hline & & $\begin{array}{c}\mathrm{K}_{\mathrm{F}} \\
(\mathrm{mg} / \mathrm{g})\end{array}$ & $\mathrm{N}$ & $\mathrm{R}^{2}$ \\
\hline & & 9 & 3 & 0.8292 \\
\hline \multirow[t]{3}{*}{ Dubinin-Radushkevich (D-R): } & \multirow{3}{*}{$y=-0.0031 x-5.9208$} & \multicolumn{3}{|c|}{ Parameters } \\
\hline & & $\mathrm{q}_{\mathrm{s}}(\mathrm{mg} / \mathrm{g})$ & $\begin{array}{c}\mathrm{E} \\
(\mathrm{kJ} / \mathrm{mol})\end{array}$ & $\mathrm{R}^{2}$ \\
\hline & & $2.68 \mathrm{E}-3$ & 12.7 & 0.8057 \\
\hline
\end{tabular}

Table 3. Pseudo-second-order kinetic model parameters and equations.

\begin{tabular}{|l|l|l|c|}
\hline F $^{-}$conc. and adsorbent dose & $\mathbf{k}_{\mathbf{2}}\left(\mathrm{g} \mathrm{min}^{-1} \mathrm{mg}^{-1}\right)$ & \multicolumn{1}{|c|}{ Rate equations } & $\mathbf{R}^{\mathbf{2}}$ \\
\hline $5 \mathrm{mg} / \mathrm{L}$ with $0.4 \mathrm{~g} / \mathrm{L}$ & $7.7064 \times 10^{-2}$ & $\mathrm{t} / \mathrm{q}_{\mathrm{t}}=0.1804 \mathrm{x}+0.4223$ & 0.9999 \\
\hline $10 \mathrm{mg} / \mathrm{L}$ with $0.8 \mathrm{~g} / \mathrm{L}$ & $12.2453 \times 10^{-2}$ & $\mathrm{t} / \mathrm{q}_{\mathrm{t}}=0.1757 \mathrm{x}+0.2521$ & 1.0000 \\
\hline $20 \mathrm{mg} / \mathrm{L}$ with $1.6 \mathrm{~g} / \mathrm{L}$ & $9.4862 \times 10^{-2}$ & $\mathrm{t} / \mathrm{q}_{\mathrm{t}}=0.1685 \mathrm{x}+0.2993$ & 0.9999 \\
\hline
\end{tabular}


Table 4. Comparison of adsorption capacity of selected adsorbents.

\begin{tabular}{|c|c|c|c|}
\hline Adsorbents & $\begin{array}{c}\text { Adsorption } \\
\text { capacity (mg/g) }\end{array}$ & $\begin{array}{c}\text { Equilibrium } \\
\text { time (h) }\end{array}$ & References \\
\hline Activated alumina (grade: A-25) & 1.78 & 6 & {$[37]$} \\
\hline Activated alumina (grade: AD101-F) & 0.415 & 10 & {$[30]$} \\
\hline AO & 23.70 & 1 & {$[13]$} \\
\hline MOCA & 1.10 & 3 & {$[30]$} \\
\hline $\begin{array}{c}\text { Zirconium Impregnated coconut shell } \\
\text { carbon }\end{array}$ & 6.41 & 6 & {$[43]$} \\
\hline $\begin{array}{c}\text { Al and Fe dispersed in porous granular } \\
\text { ceramics }\end{array}$ & 1.79 & 48 & {$[44]$} \\
\hline $\mathrm{KMnO}_{4}$ modified carbon & & & {$[45]$} \\
\hline ABC & 15.9 & 3 & Present study \\
\hline AIAABC & 4.32 & 3 & Present study \\
\hline
\end{tabular}


Page 22 of 29

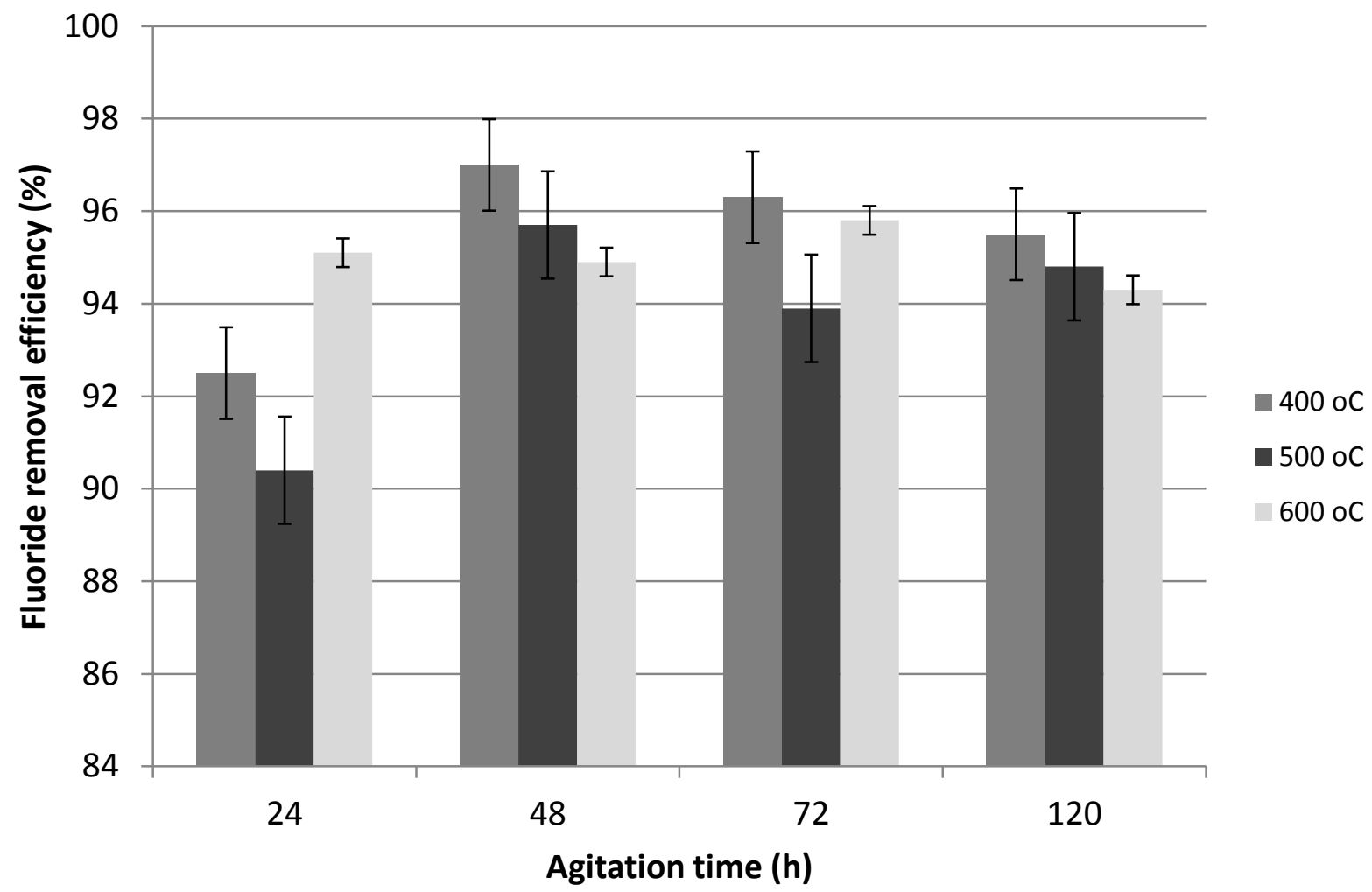

Fig. 1. Effect of activation and agitation time on fluoride removal efficiency of AIAABC (activation chemical; $\mathrm{AlCl}_{3} / \mathrm{FeCl}_{3}$, adsorbent dose $=1.6 \mathrm{~g} / \mathrm{L}$, initial fluoride concentration $=10 \mathrm{mg} / \mathrm{L})$. 
Page $\mathbf{2 3}$ of 29
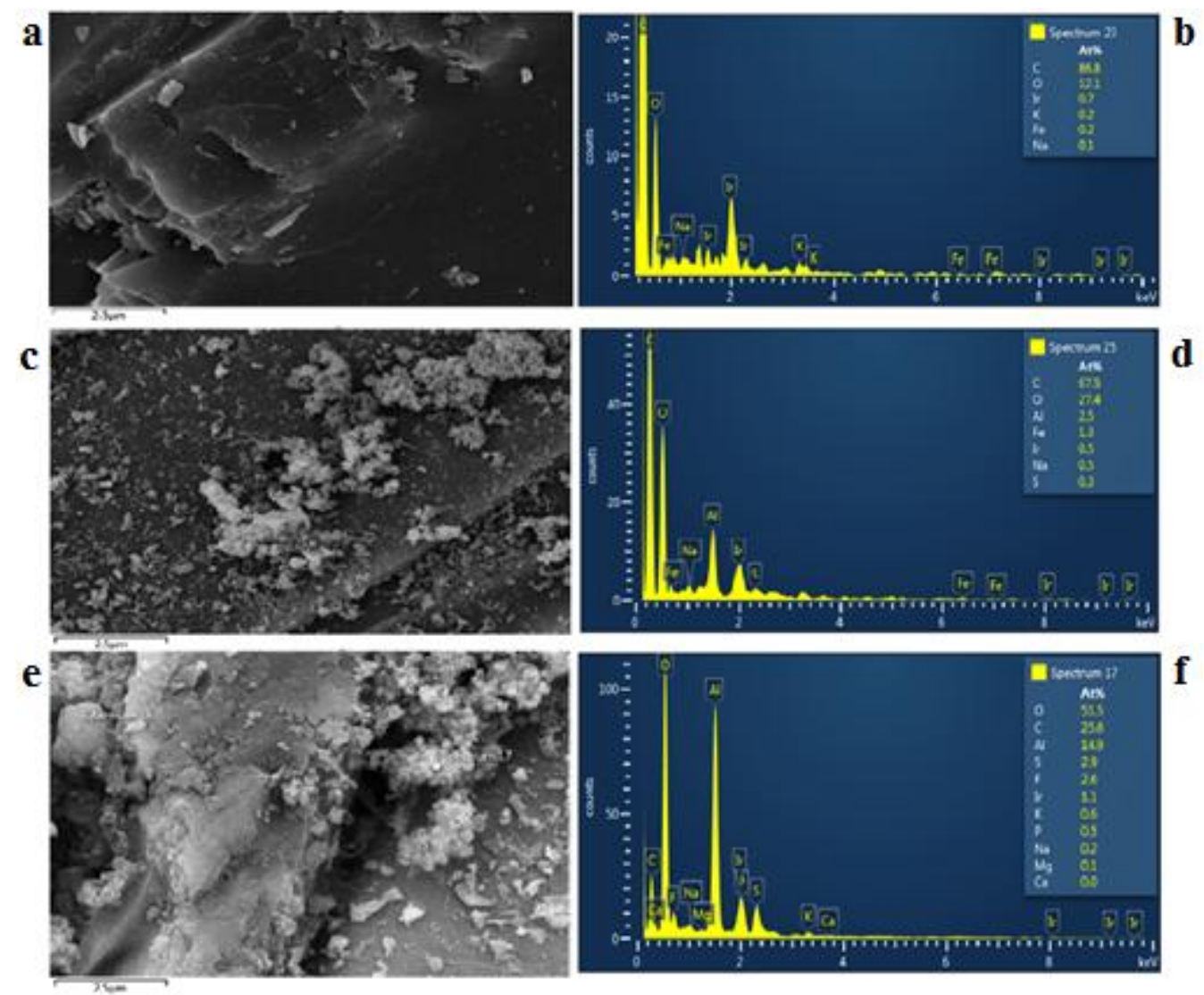

Fig. 2. SEM and EDS of $A B C(a, b), A I A A B C / b e f o r e(c, d)$ and after $(e, f)$ fluoride adsorption $($ SEM magnification; $(\mathrm{a}, \mathrm{c}$ and $\mathrm{e})=10,000 \mathrm{x})$. 
Page 24 of 29

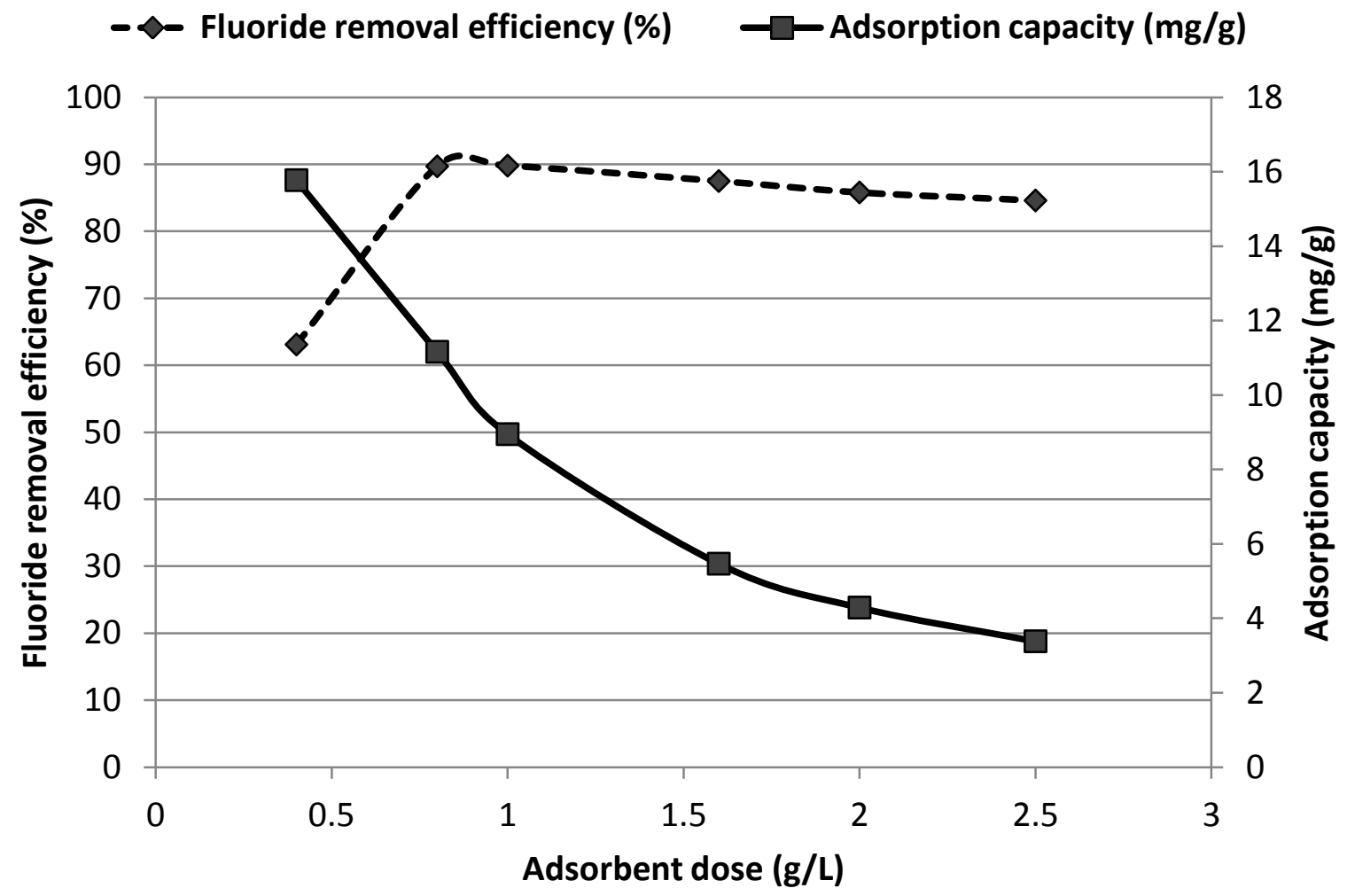

Fig. 3. Adsorption capacity and $\%$ of fluoride removal as a function of adsorbent dose (initial fluoride concentration $=10 \mathrm{mg} / \mathrm{L}$, contact time $=180 \mathrm{~min}$, and $\mathrm{pH}=7.0 \pm 0.2$ ) 
Page $\mathbf{2 5}$ of 29

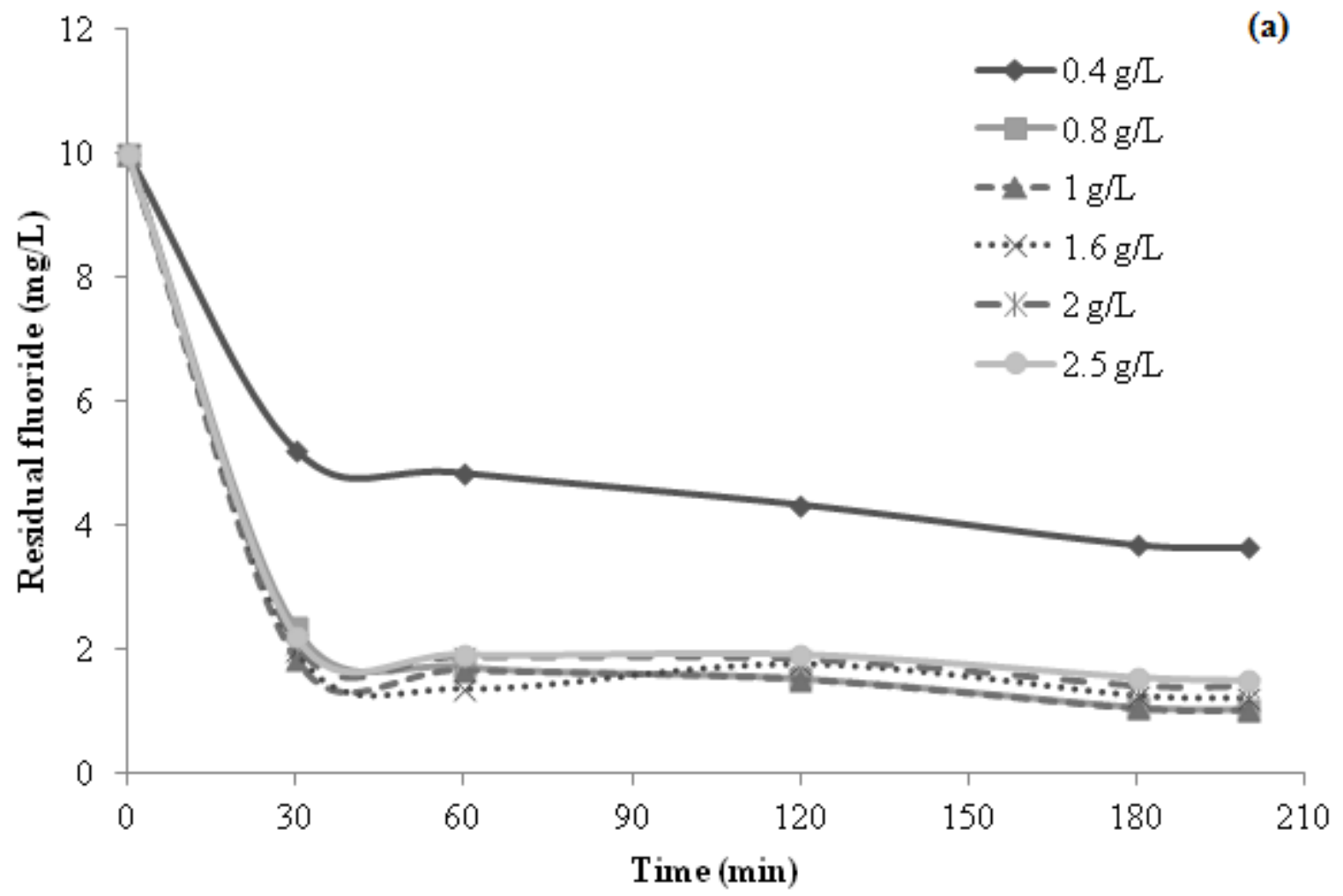

(b)

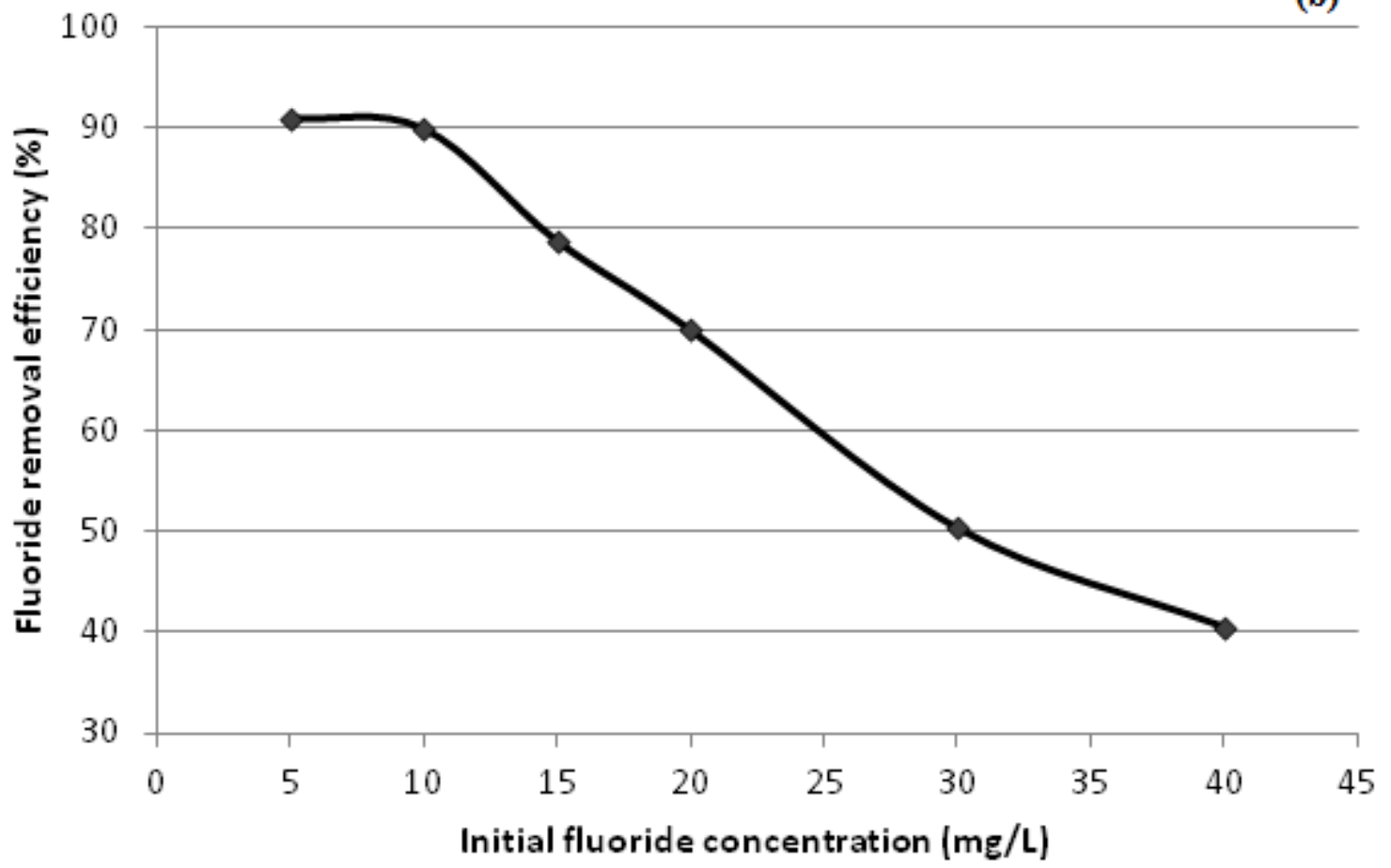

Fig. 4. (a) Effect of contact time on the adsorption of fluoride on AIAABC (initial $\mathrm{F}^{-}$ concentration $=10 \mathrm{mg} / \mathrm{L}$ ); (b) effect of initial fluoride concentration on removal efficiency by AIAABC $($ dose $=0.8 \mathrm{~g} / \mathrm{L}$, contact time $=180 \mathrm{~min})$. 
Page 26 of 29

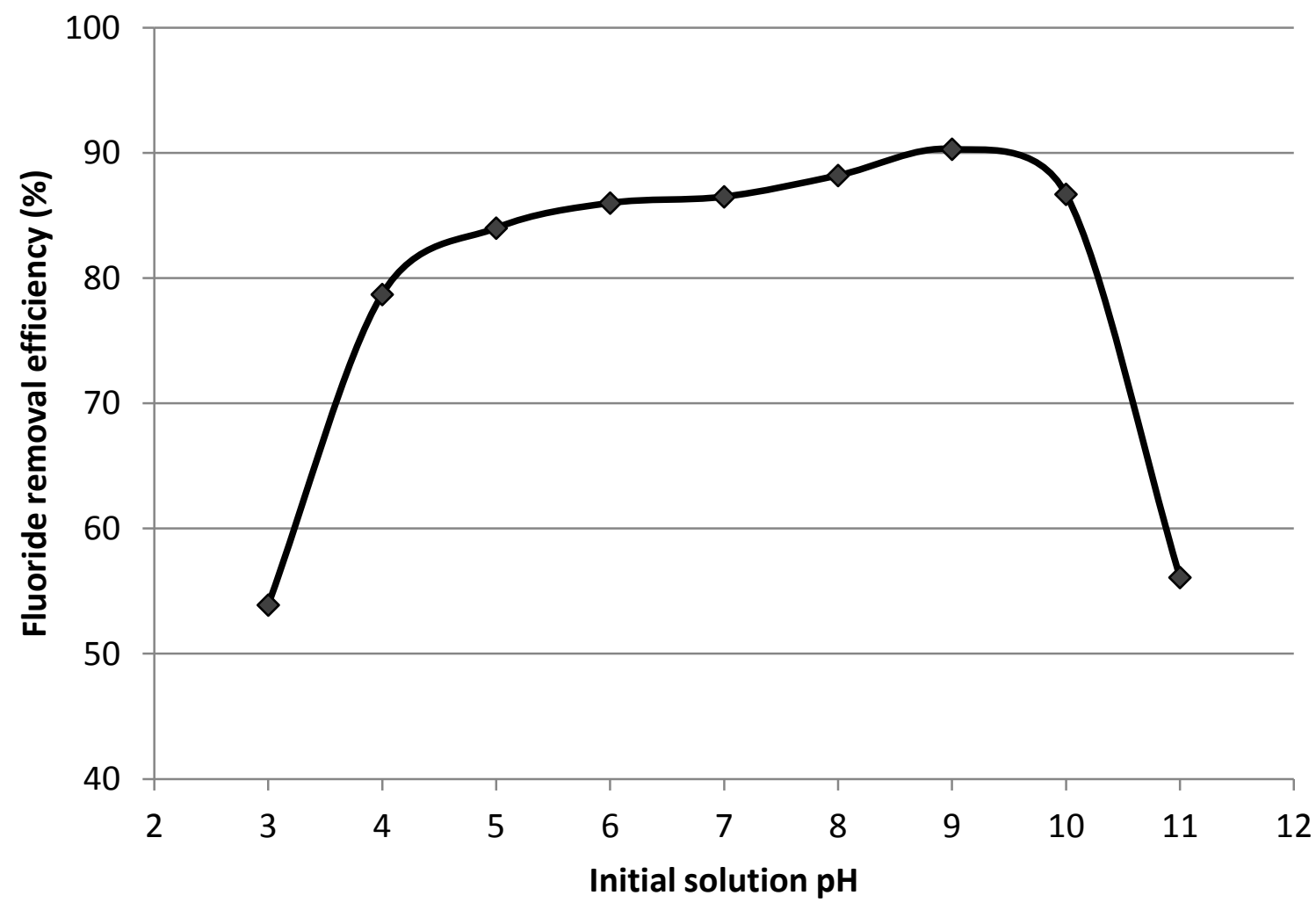

Fig. 5. Effect of initial solution $\mathrm{pH}$ on fluoride removal efficiency (initial $\mathrm{F}^{-}$concentration $=10$ $\mathrm{mg} / \mathrm{L}$, adsorbent dose $=0.8 \mathrm{~g} / \mathrm{L}$, and contact time $=180 \mathrm{~min})$. 
Page 27 of 29

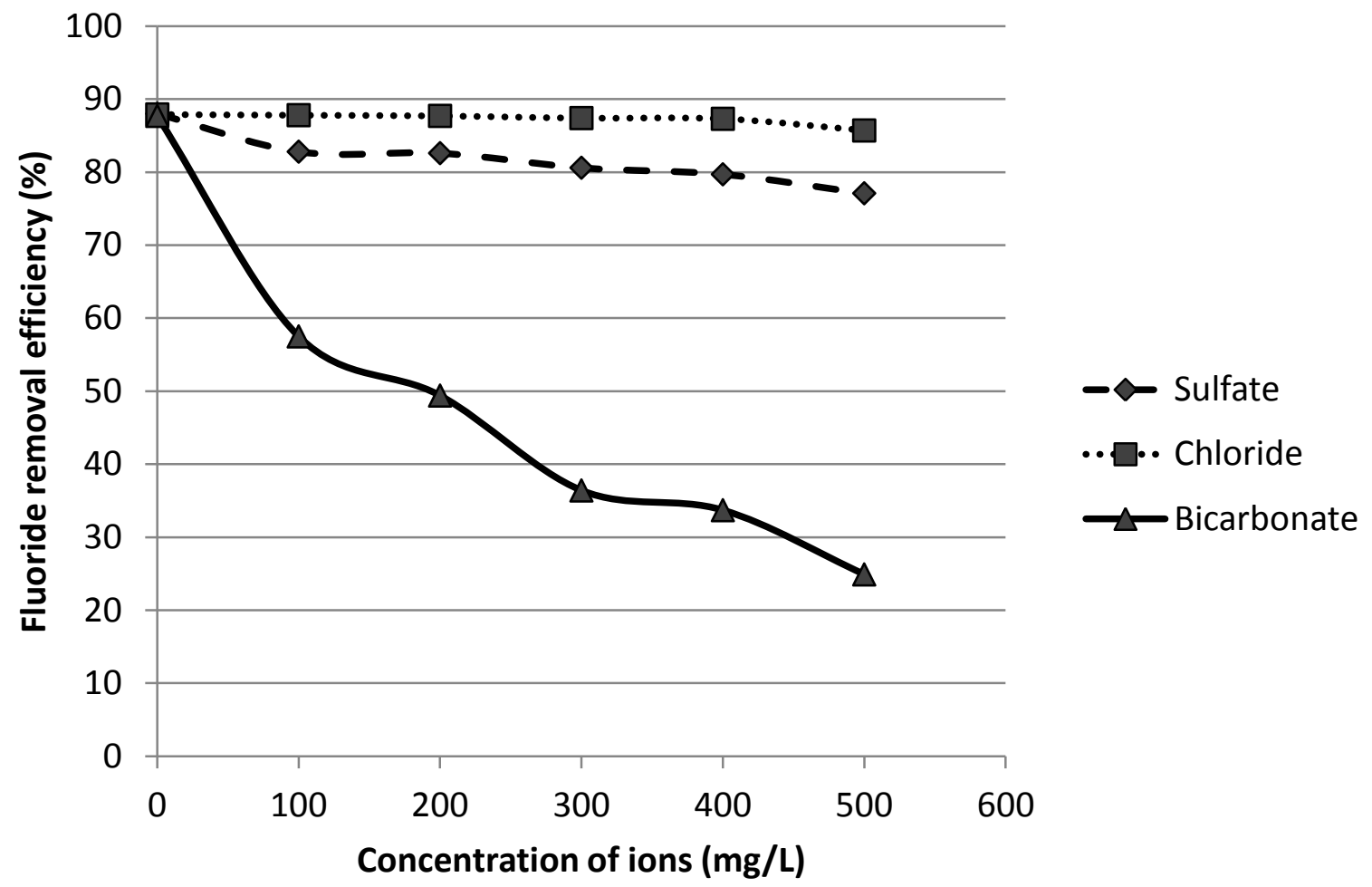

Fig. 6. Effect of co-existing anions on fluoride removal efficiency of AIAABC ( $\mathrm{pH}=7.0 \pm 0.2)$. 
Page 28 of 29

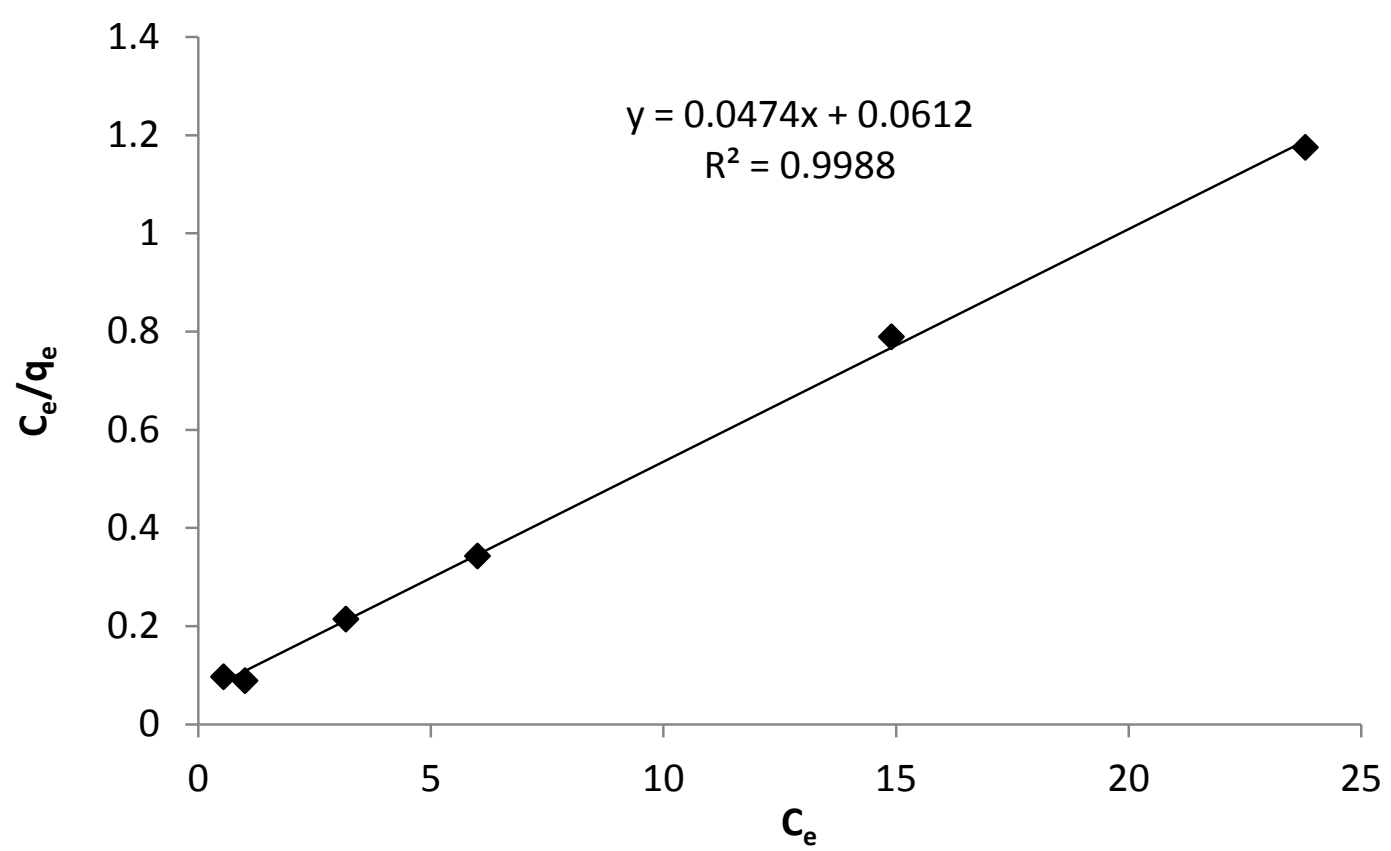

Fig. 7. Linearized Langmuir isotherm of the adsorption process (adsorbent dose $0.8 \mathrm{~g} / \mathrm{L}$, contact time $=3 \mathrm{~h}$, and $\mathrm{pH}=7.0 \pm 0.2$ ).

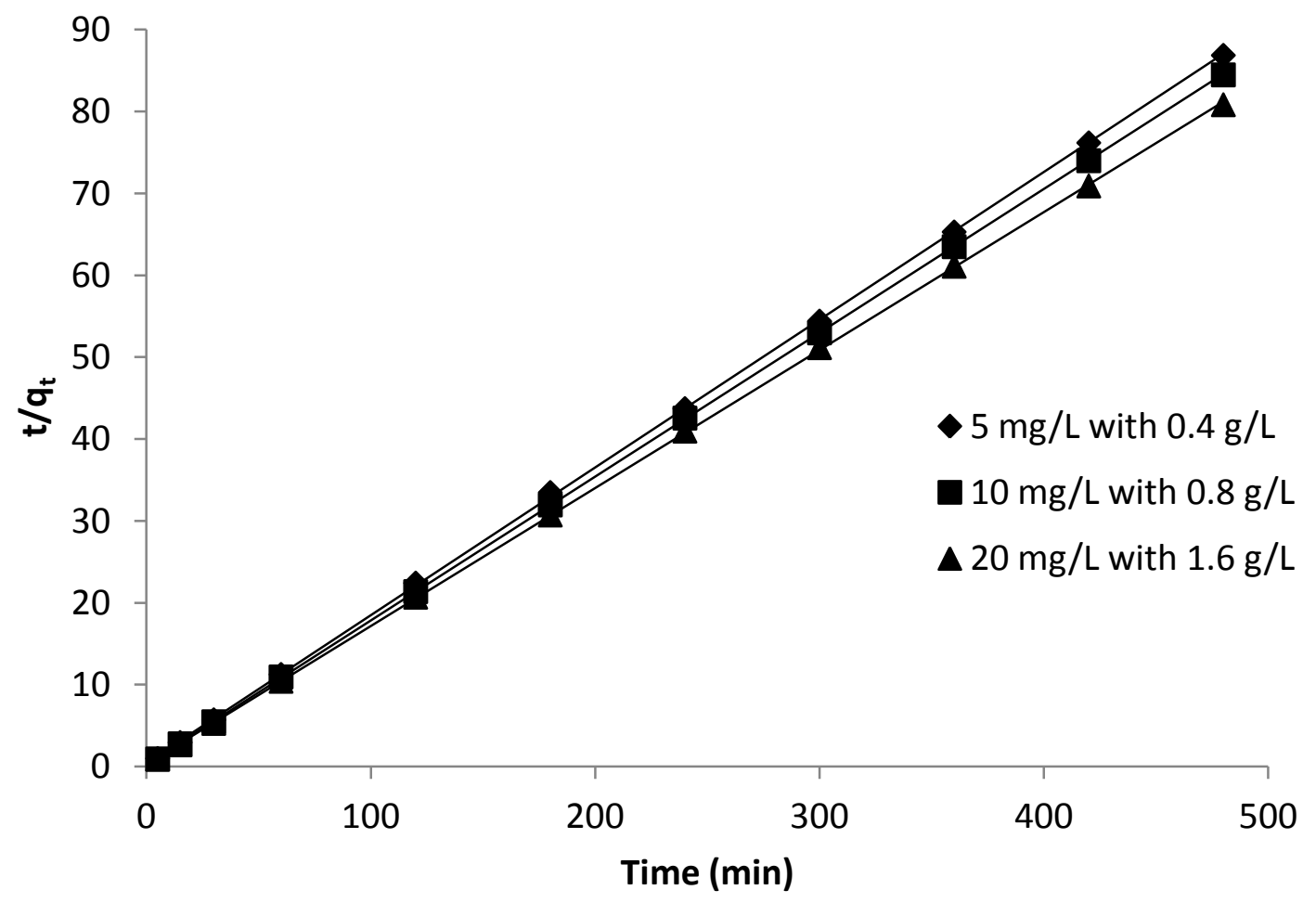

Fig. 8. Linear pseudo-second-order kinetics for the adsorption of fluoride on AIAABC with initial fluoride concentrations of $5 \mathrm{mg} / \mathrm{L}, 10 \mathrm{mg} / \mathrm{L}$, and $20 \mathrm{mg} / \mathrm{L}$, to adsorbent doses of $0.4,0.8$, and $1.6 \mathrm{~g} / \mathrm{L}$, respectively $(\mathrm{pH}=7.0 \pm 0.2$ and contact time $=3 \mathrm{~h})$. 
Page 29 of 29

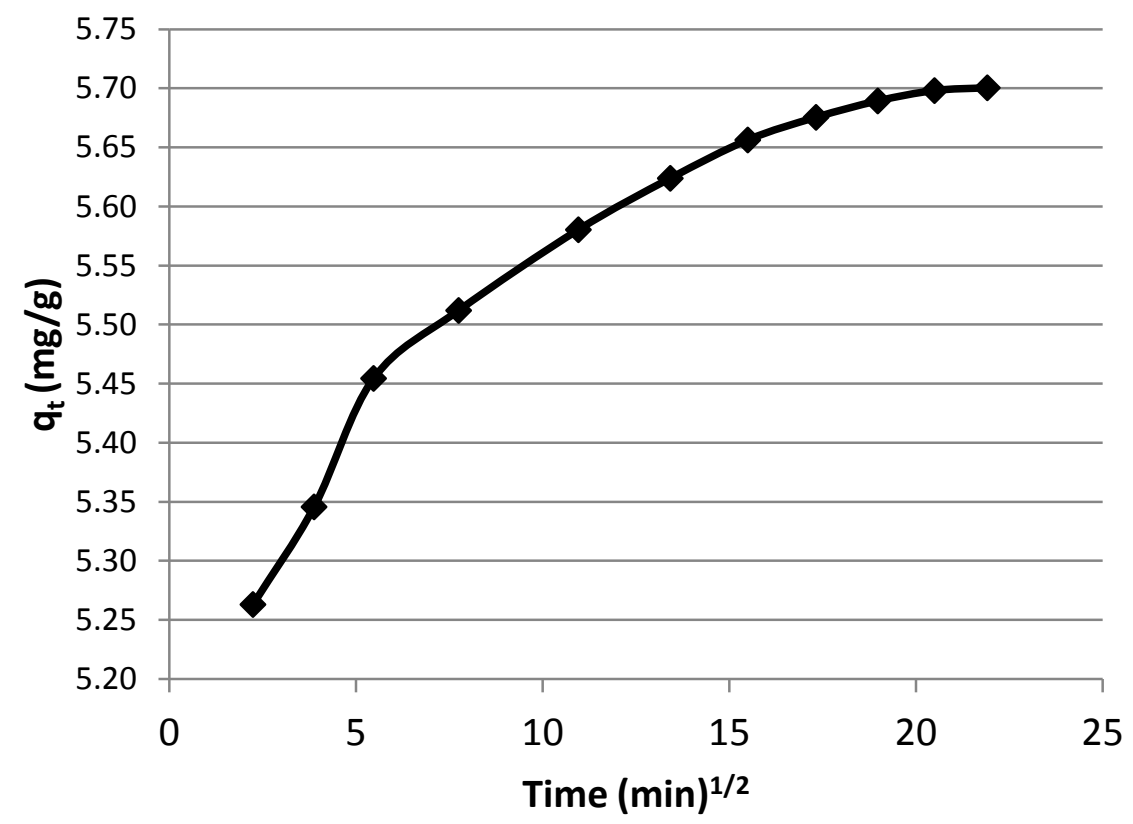

Fig. 9. Adsorption capacity $(\mathrm{mg} / \mathrm{g})$ as a function of square root of Time $(\mathrm{min})^{1 / 2}$.

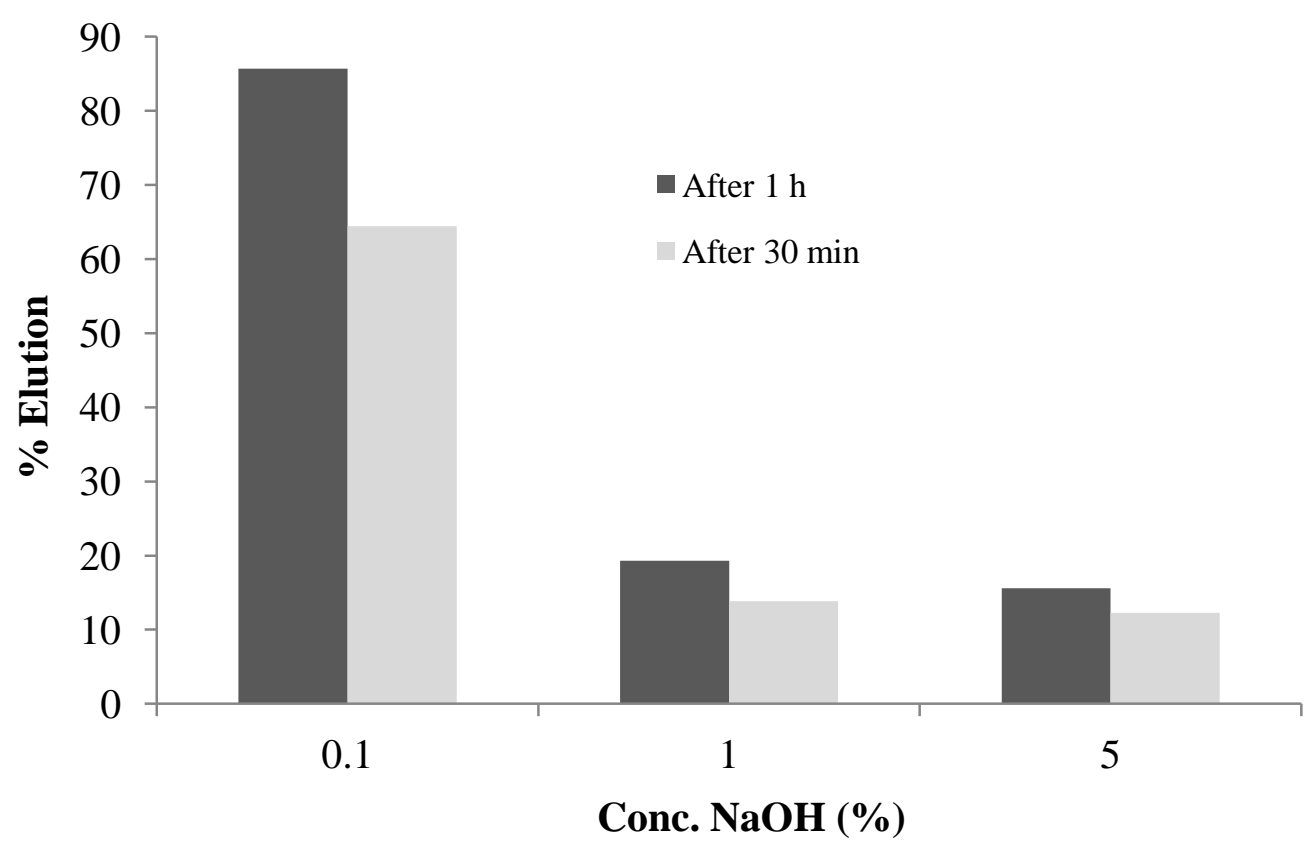

Fig. 10. Percentage of fluoride eluted with different concentrations of $\mathrm{NaOH}$ and time (Adsorbent dose $=0.8 \mathrm{~g} / \mathrm{L}$, initial fluoride concentration $=10 \mathrm{mg} / \mathrm{L}$ ). 